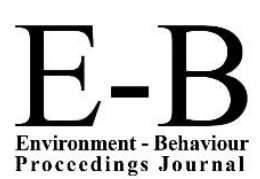

Procecdings Journal

\section{AicE-Bs2015Barcelona}

$6^{\text {th }}$ Asia-Pacific International Conference on Environment-Behaviour Studies, Barcelona School of Architecture (ETSAB), Barcelona, Spain,31 Aug.- 05 Sep. 2015

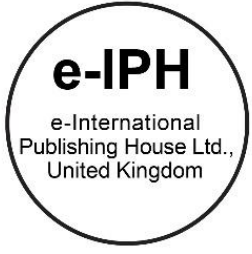

\title{
Virtual Environment as a Design Tool for Sustainable Residential Spaces in Light of Theory of Planned Behavior
}

\author{
Hebatalla Sherin Nazmy *
}

Interior Architecture, Faculty of Fine Arts, Helwan University, Mohamed Thakeb Street, Zamalek 11561, Ciro, Egypt

\begin{abstract}
This study aims to reveal the impact of Virtual Environment as a design tool on the interior architect's design behavior towards adopting sustainable residential interior design practices. This approach is guided by the Theory of Planned Behaviour as a theoretical framework; the purpose as such would serve to bridge the gap between theoretical knowledge and its practical implementation to promote sustainable design practices. Findings revealed that Virtual Environment is anticipated to assist the interior architect in integrating the complex sustainable residential design objectives, and thus positively affect the interior architect's behavioral performance towards embracing sustainable residential design solutions.
\end{abstract}

(C) 2016. The Authors. Published for AMER ABRA by e-International Publishing House, Ltd., UK. Peer-review under responsibility of AMER (Association of Malaysian Environment-Behaviour Researchers), ABRA (Association of Behavioural Researchers on Asians) and cE-Bs (Centre for Environment-Behaviour Studies, Faculty of Architecture, Planning \& Surveying, Universiti Teknologi MARA, Malaysia.

Keywords: Virtual Environment; Residential Spaces; Sustainable Design; Theory of Planned Behavior

\section{Introduction}

The way in which the house is designed to operate represents a physical expression of the personal beliefs, values, and conditions of its designer as well as its future occupants. Previous research found out that residential buildings play a huge role in fuel and energy consumption, as well as greenhouse emissions, where the main consumers are building users. Accordingly, it is a critical time for interior architects to be at the forefront of creating sustainable residential environments. Although the sustainable design has become one of the major concerns in the interior design industry, yet the frequency of making sustainable decisions in real practice is still limited. In that sense, this study aims to identify factors and motivations affecting the sustainable residential design. Furthermore, this study intends to highlight the role of the virtual environment as a design tool in promoting sustainable design practices in residential context.

\footnotetext{
${ }^{*}$ Corresponding author. Tel.:+2-012-23455564

E-mail address: hebanazmi@gmail.com
} 


\section{Methodology}

The methodology adopted literature review with an analysis of theory of planned behavior constructs, sustainable residential design characteristics, and virtual environment conveniences. By overlaying results, the research investigates the influence that could be caused by virtual environment on the designer's perception of control and intention and how it is consequently expected to affect behavioral performance in order to produce sustainably enhanced residential interior design.

\subsection{Theory of Planned Behavior}

Ajzen and colleagues developed the Theory of Planned Behavior (TPB) in 1985. It offers one of the most established theories in the field of environmental phycology (Howell, 1976). Azjen based the TPB on theoretical concepts concerned with individual's cognitive factors such as attitude toward the behavior, the normative social perception regarding it, as well as perceived control. Each determinant has its individual belief structure: behavioral beliefs for attitude, normative beliefs for subjective norms, and control beliefs for perceived behavioral control (Glanz, et al., 2008).

Azjen established the perceived control construct on the idea that behavioral performance is determined by motivation together with the ability to perform it. Perceived control is determined by control beliefs concerning the presence or absence of facilitating or constraining conditions that affect the performance of the behavior, weighted by their perceived power or the impact of each control factor to facilitate or inhibit the behavior. TPB also postulates that perceived control is an independent determinant of behavioral intention, along with attitude toward the behavior and subjective norm. Holding attitude and subjective norm constant, a person's perception of the ease or difficulty of behavioral performance will affect his behavioral intention.

\subsection{Residential Design}

Residential interior architecture is about creating spaces for habitation, in which its residents can develop in physical emotional, mental and spiritual health. It represents a complex problem with multi-dimensional objectives and competing requirements (Bako, 2012). Accordingly, its successful executions depend on the incorporation of life sciences (Jones, 1980). The residential interior architectural design is the process of creative form determination seeking the visual creation with the resolution of practical needs and sustainable considerations. The interior architect seizes the optimum solution to the sum of the true needs of a particular set of circumstances through developing a framework of intentions (Pile, 2007; Jones, 1980; Lawson, 1980).

\subsubsection{Process and Activity}

Design method consists of a cognitive process together with physical activity as shown in Fig. 1. The cognitive process takes place in the designer's mind. It involves problem statement (analysis), tentative solution (synthesis), criticism (evaluation) and refinement of one or more of the tentative solutions (development) and results in creative ideas (Smithies, 198; Lawson, 1980). The physical activities implement ideas and make it appear in its final form and can be observed by outsiders where the designer goes through a sequential pattern of stages. Beginning with gathering information related to the project (program brief), moving to (conceptual design), and then developing (schematic design) and ending with (detail design) (Lawson, 1980). 


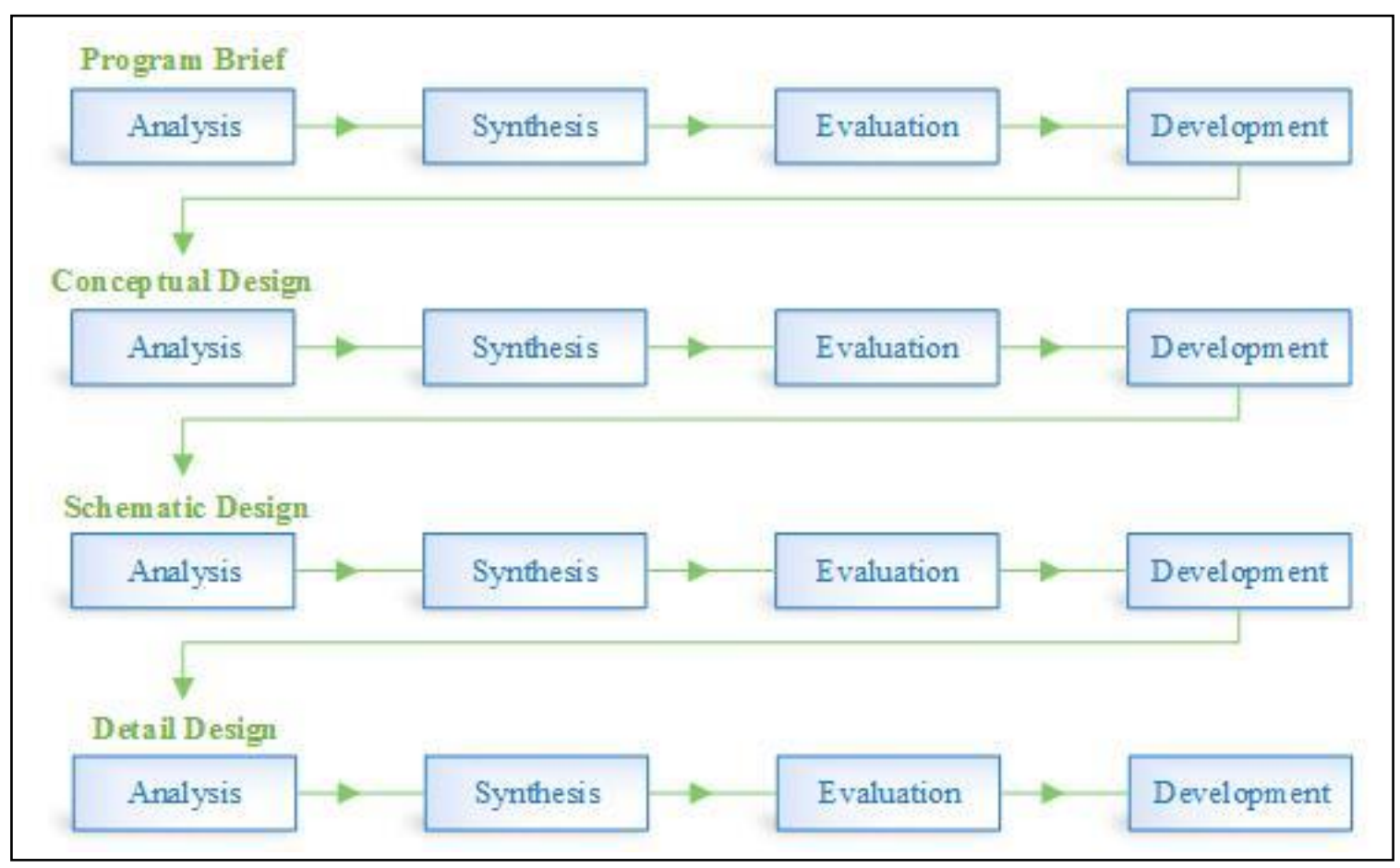

Fig. 1. Residential design workflow (Source: Nazmy, 2013)

\subsubsection{Aesthetics, Function, and Sustainability}

Residential design is concerned with creating spaces that enrich the occupants through sensory experience and perception of the high level of emphasis placed on aesthetics (Pieter den Hartog, 2004). Appearance is largely dependent on how interior architectural elements such as are put together (Unwin, 1997). One of the most important tasks of the interior architect is to establish the right priorities of design principals and be able to maintain them throughout all the design stages (Smithies, 198; Unwin, 1997; Pile, 2007). The interior architect is also expected to have the ability to create a geometry that possess and innate capacity contributing to the identification of the place and to influencing their surroundings.

A residence includes a combination of areas that embraces all pragmatic requirements that enables the occupants to perform various daily life activities. In contemporary residential architecture, the outside design is determined from the parametric requirements and relationships of the inside areas. The size of spaces is identified by activities done in them and by some other features. Thus, the interior architect adopts parametric design methods to integrate all design requirements with respect to functional aspects (Suyoto, et al., 2015). This involves the conceptual orientation and physical arrangement of the world into places. All of these interrelated aspects plays an important role in the final result of the designed space.

Residential interior architecture involves creating a relationship between the "insides" and "outsides" together with the "human being". The different lifestyles of occupants have a direct impact on the environment. Thus, creating sustainable residential spaces requires serious design thinking aiming to collaborate with the natural physical conditions and to wisely use of resources to create self-sufficient residential spaces (Unwin, 1997; Mahmud, et al., 2012). The United States Green Building Council (USGBC) created a green building rating system known as LEED®, an acronym that stands for the Leadership in Energy and Environmental Design. Indoor Environment Quality (IEQ) is one of the Leadership in Energy and Environmental Design (LEED) rating categories. It aims to minimize the energy consumption and the indoor air pollution through enhancing the indoor air quality, thermal comfort, lighting, and acoustics. 


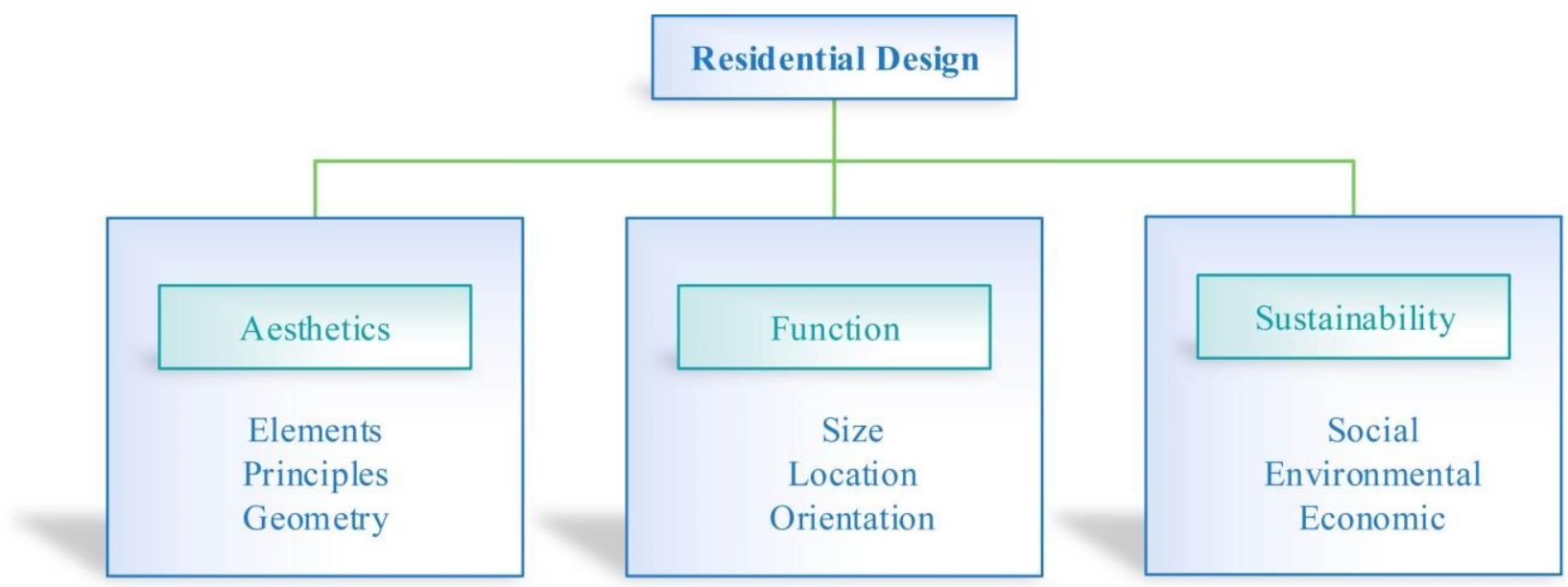

Fig. 2. Residential design aspects (Source: Nazmy, 2013)

\subsection{Virtual Environment}

Designers have increasingly invested in graphic interpretations of design alternatives to understand present facts and predict future possibilities of spatial aspects of the proposed built environment (Dong, 1998). Conventional methods of representation limited in their capacity, as they focus on static relationships and fail to represent neither dynamic situations nor natural phenomena. Many researchers, architects, and software developers desired the design experience in which that the designer is allowed to design directly in three dimensions. The virtual environment provides 3D models that are geometrically consistent, comprehensive, intelligent and integrated and synchronized. It can be a foundation for further studies aiming at enhancing the design and performance of the residential built environment (Ken Sanders, 1996).

\subsubsection{Medium and System}

The virtual environment is based on creating the spatial illusion of three-dimensional space where the participant can perceive the surrounding environment and navigate and interact with it to perform specific tasks in real time. Virtual Environment medium denotes the database that is comprised of data sets, generating the three-dimensional workspace obeying its own mathematics rules to create models variable attributes of natural phenomena and physical behavior and performance aids that provides the user with a range of tools to enhance the performance which makes it indistinguishable from the real world (Bertol, Daniela \& Foell, David, 1997; Whyte, 2002).

The virtual environment system attempts to create an intuitive interface through which the human- computer interaction could happen. The success of the virtual environment experience depends on the participant's level of achievement of natural perception and physical immersion provided by the virtual environment system which consists of advanced hardware and software, input and output devices, and data and users as shown in Fig. 2. Developing virtual environment system involves different disciplines aiming at involving the human five senses of sight, sound, touch, smell, and taste. In which the human body is equipped in order to act as a device providing a man-machine relationship providing body and senses extensions and seeking an intuitive perception and interaction with the surrounding virtual environment (Bertol, Daniela \& Foell, David, 1997; Whyte, 2002). 


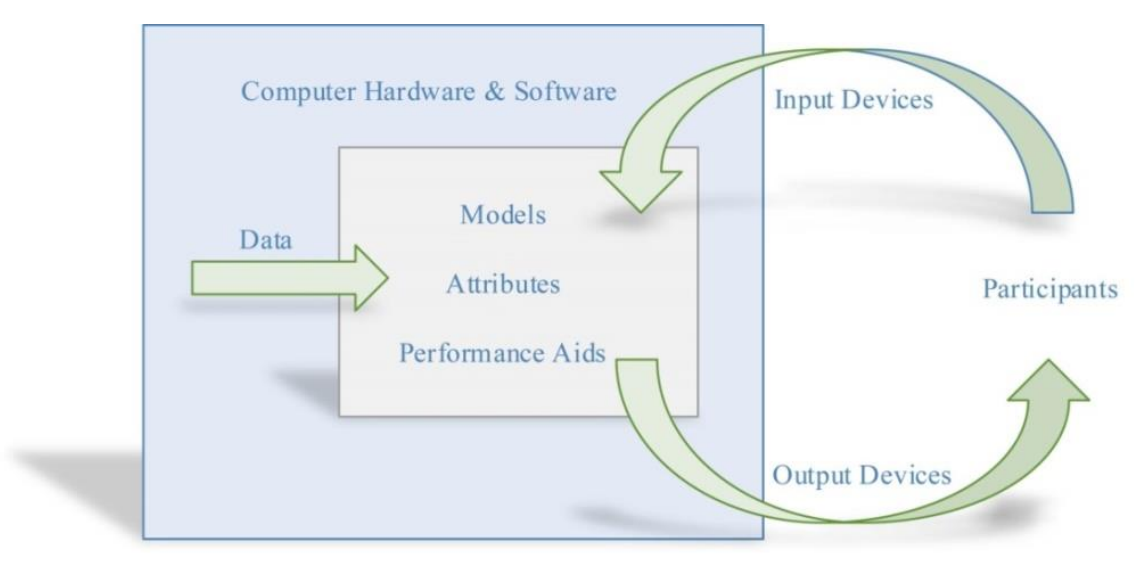

Fig. 3. Virtual environment components (Source: Nazmy, 2013)

\subsubsection{Facilities and Capabilities}

Virtual Environment provides designers with and immersing virtual space in which they can intuitively navigate and interact with a virtual three-dimensional interface, in which they experience a realistic rendering of full-scale representations of interior architectural elements (Bertol, 1997; Dong, 1998; Memikoğlua, 2014). Three-dimensional models and their associated database contribute to the design process by providing intelligent and accurately coordinated design information and producing quick and accurate drawings which ease the transition from design to construction (Dong, 1998; Whyte, 2002). Simulation using computergenerated models is a unique and effective way of analyzing interior architectural characteristics of residential spaces and the impact they will have on the built environment (Bertol, 1997).

Virtual Environment technology has changed the professional practices of interior architectural design. In which design ideas are encapsulated in digital media and represented in the form of digital data that is known of its malleability, articulacy, accessibility, and accuracy. The virtual environment facilitates the design modification that takes place when investigating the suggested tentative solutions. Design presentation using virtual environment keeps the designer aware of the detailed visual inter-relationships between all the parts of the building. The virtual environment plays an important role in the design coordination required to avoid changes in the design at a late stage. Virtual environment aids the design evaluation is a complex process of analyzing all aspects of the proposed design (Bertol, 1997; Smithies, 1981; Pile, 2007).

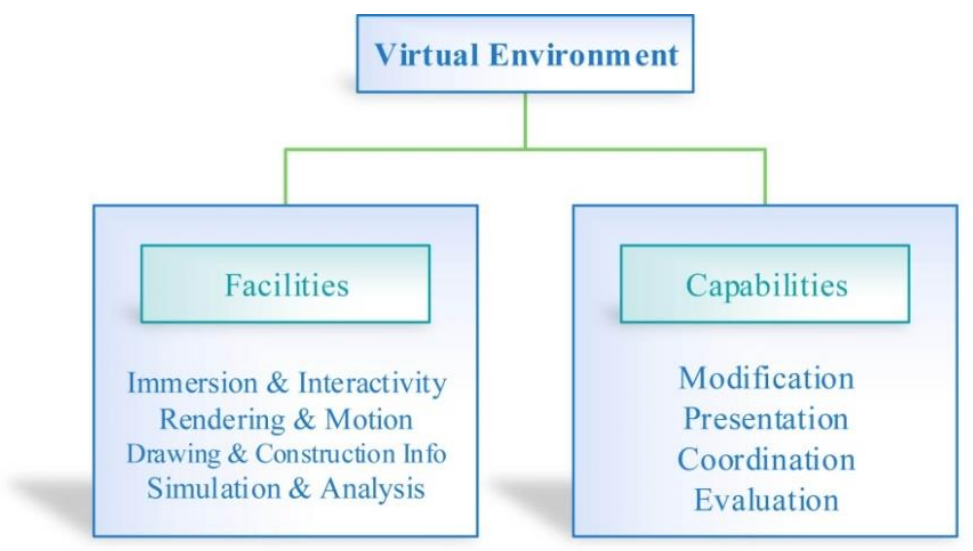

Fig. 4. Virtual environment advantages (Source: Nazmy, 2013) 


\section{Findings}

In residential conceptual space design it is needed to transfer the dominating idea from the designer's mind to an external from by means of a tangible representation in order to bring all of the diverse parts of design into a strong relationship based on an initial set of design criteria (Pile, 2007; Porter, 1979). Virtual environment revealed a marked tendency in the conceptualization of form, through providing an immersive interactive three-dimensional media of representation, approximating the human experience of spatial impression. VE allows the interior architects to modify the design dynamically while exploring its nature and at the same time it provides them with timely design feedback, which leads to the creation of innovative and intellectual sustainable residential interior architectural forms (Whyte, 2002; Dong, 1998; Porter, 1979; Bertol, 1997).

During designing residential spaces communication problems may arise since it is collaborative effort of the designer together with the clients and participants from different disciplinary fields, each one responsible for specific tasks within an overall framework (Pieter den Hartog, 2004; Coleman, 2002; Lawson, 1980; Haddad, 2014). The virtual environment provides a natural method of communication through participatory design. Design team members, clients, consultants, and legislators are allowed to cooperate by graphically illustrating visual images in the mind through experiencing an orientation replica of the intended built environment before its physical construction. Hence, the interior architect could synthesize the various sustainable design ideas and conflicting criteria (Dong, 1998; Whyte, 2002; Ken Sanders, 1996; Bertol, 1997; Kim, 2015; Norouzia, 2015; Coleman, 2002).

In residential interiors, the experience of space is radically affected by the visual aspects that have a powerful and continuing effect on the mind of the observer (Smithies, 1981). The virtual environment allows the visualization of mental pictures by the aid of rendered design data, which leads to the manifestation of the suggested design idea. It also enables the real-time navigation and interaction with the virtual spatial world using different types of viewing perspectives and navigation modes. Allowing the designer to consider various alternatives, identify interrelation conflicts, and explore new solutions, and thus, the designer is better able to understand, analyze, and implement sustainable design decisions (Dong, 1998).

The provision of initial utility goals for is a critical part of the residential design problem. The considerations needed for human movement, vision, light, ventilation, temperature, humidity and sound and safety and stability are major determinants of interior spaces arrangements (Smithies, 1981; Unwin, 1997; Whyte, 2002; Dong, 1998; Jamaludina et al., 2015). The virtual environment is the methods of experimentation that helps in simulating, analyzing and assessing the performance of the proposed design solution, and thus identifying errors early in the process (Porter, 1979). The virtual environment supports innovative designers by providing them the opportunity to perform indepth experimentation of performance sustainable characteristics.

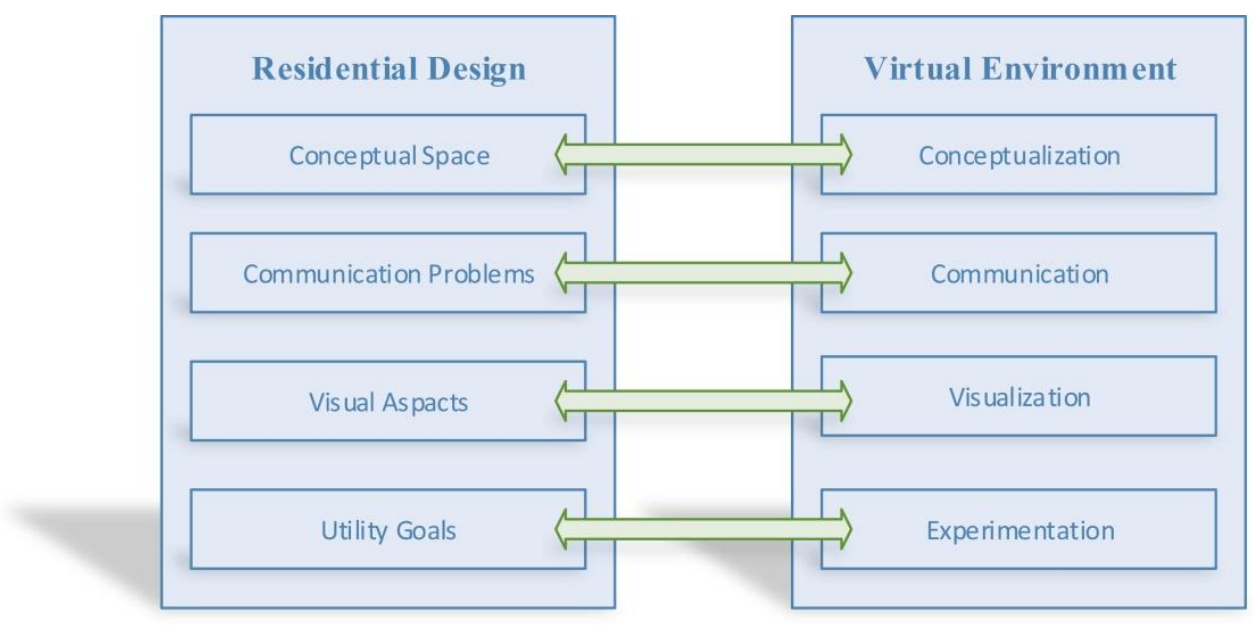

Fig. 5. Relation between residential design and virtual environment (Source: Nazmy, 2013) 


\section{Discussion and Conclusion}

According to the TPB determinants (attitude, subjective norms, and perceived control), interior architects are more likely to adopt a sustainable residential design driven by behavioral intentions, when they have positive beliefs and towards sustainable residential design benefits and when they perceive their building industry favor them to perform sustainable residential practices, in addition to the amount of control they believe to have over sustainable residential goals (Glanz, et al., 2008; Lee, et al., 2013).

\subsection{Sustainable Residential Design}

Residential design problems are perceived differently depending to a certain extent on the designer's behavioral beliefs towards solving them (Lawson, 1980). The increasing levels of energy, carbon, water use and waste cost savings announced by the USGBC green building average analysis, as well as the verified performance, increased value, reduced liability and improved risk management and developed productivity has positively affected the interior architect's pro-environmental beliefs and thus directs his intentions and behavioral performance towards adopting sustainable residential design.

\subsection{Sustainable Triple Bottom Line}

The triple bottom line represents business drivers of the building industry that leads the interior architect's normative beliefs towards adopting sustainable residential practices. The triple bottom line summarizes the concept of green buildings. It promotes its values and benefits, focusing on the positive impacts on environmental, economic, and health and community systems over the life cycle of a building (Cottrell, 2014; Abdel-Hadi et al., 2012). Efficiency and sustainability are the main goals of green design, aiming at enhancing the quality of life by promoting the benefits of sustainable residential design for the environment as well as for the physical and psychological well-being of the occupants (Haddad, 2014; Ismail, et al., 2015; Abdel-Hadi, 2012).

\subsection{Virtual Environment for Sustainable Residential Design}

The success of performing sustainable residential design decisions depend on the sufficient level of control beliefs; represented in the designer's skills, resources, and other prerequisites needed to perform the sustainable residential design. Virtual Environment as a design tool helps in qualifying the building characteristics and judging its performance regarding sustainable criteria in advance, by the means of providing facilities and capabilities to conceptualize, communicate, visualize and experiment the design proposals. This immediate and simultaneous design tool can guide important design decisions to validate successful design implementation and optimize the performance of the real built environment.

\subsection{Intentions towards Adopting Sustainable Residential Design}

Successful performance of the behavior depends on the favorable intention of creating healthy, energy efficient and resourceeffective residential spaces. Indoor Environmental Quality represents 15 of total 69 points of LEED rating categories. It can be achieved by considering the passive architectural design features and building envelope, including building placement and orientation, massing and form, and the placement of windows and openings. An interior architect seeking sustainable strategy to improve indoor air quality tends to select sustainable construction, finishes and furnishings materials, provide a properly designed ventilation system, and comply with indoor thermal comfort criteria, provide adequate access to natural lighting and views as well as control acoustics for optimum comfort (Abdel-Hadi et.al, 2012; Husin \& Harith, 2012; Keonil \& Sahachaisaeree 2012; Isnin, et al., 2012; Mussa et al., 2012).

\subsection{Behavior towards Adopting Sustainable Residential Design Practices}

The interior architect's perception of control over virtual environment aiding sustainable design practices, together with Indoor Environmental Quality intention, is expected to have a direct effect on behavior performance. Building Information Modeling based virtual environment is an integrated workflow that allows the superimposing of reliable, coordinated multi-disciplinary 
information about a project from design through construction and into operations within one model. Therefore, it is an accurate assessment of actual control over the behavior (Glanz, et al., 2008). BIM creates the opportunity for the interior architect to conduct in-depth sustainability analysis based on building's context, form, and materials. Thus, empowers the designers against

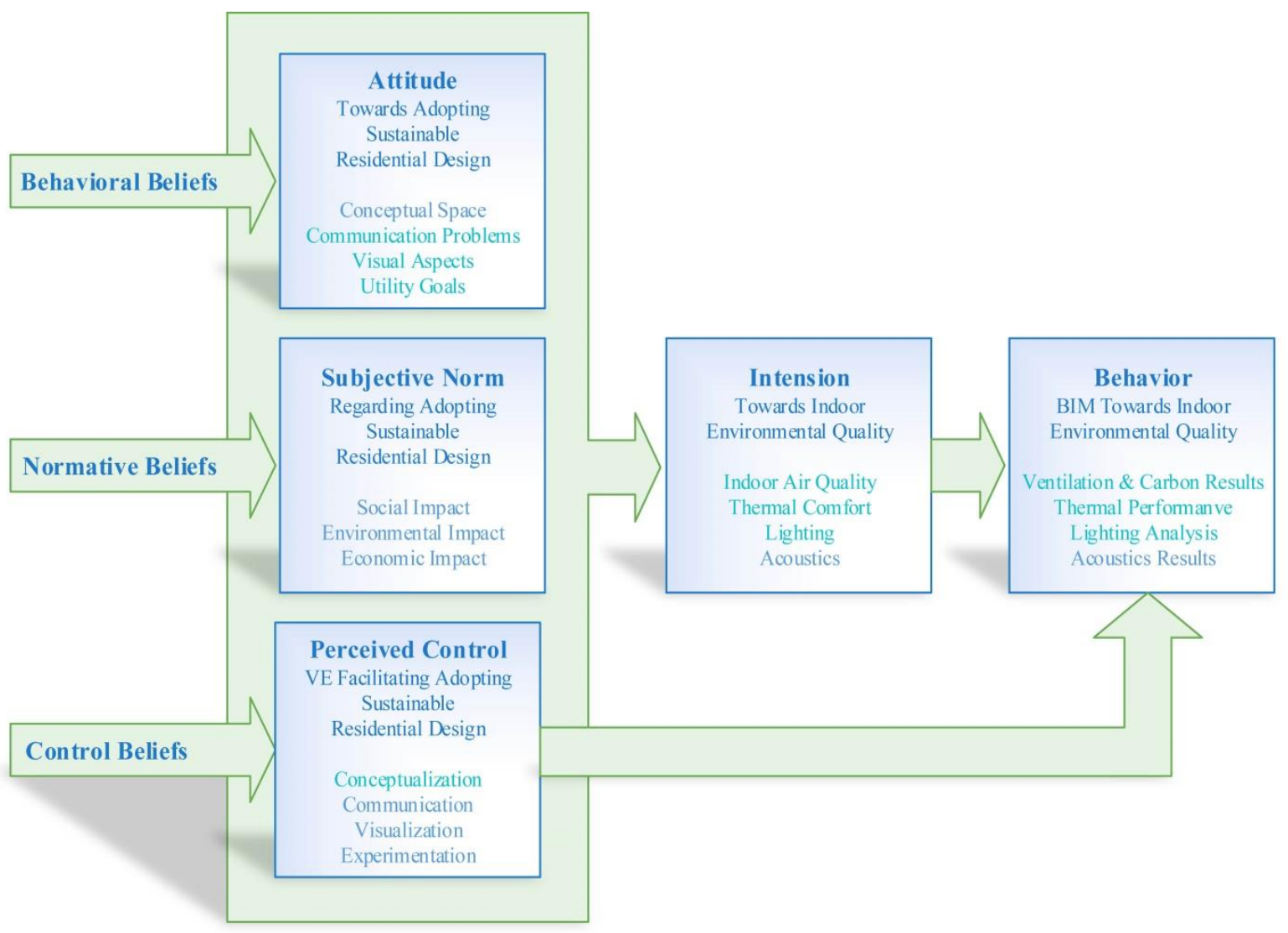

sustainability in areas where they do not have sufficient knowledge or competence themselves aiming at aiding them making informed sustainable design decisions from the earliest possible design stages (Azhar, 2012; Abo Neama, 2012).

Fig. 6. TPB explaining VE's control over the interior architect's behavioral performance to adopt sustainable practices 


\section{Implications, Limitations, and Future Research}

The primary goal of the interior architect is to provide the occupants of the house with a means not an end; the house is constructed to embrace an on-going stream of activities. The interior architect is expected to consider internal constrains such as well as external constrains simplified in sustainability issues that regulate the relation between the House and nature around it. After all, sustainability is one leg of the three-legged residential design stool; the other two legs are aesthetics and function. Without its third leg, the stool falls. TPB helps explain contradictions between sustainable attitudes and unsustainable behavior and provide valuable insights for developing more effective strategies to strengthen the interior architectural design curriculum thus encourage the adoption of sustainable design practices by the homebuilding industry. According to TPB, successful performance of a sustainable residential design depends not only on the favorable intention of the interior architect towards adopting sustainable residential design, but also to the level of ease or difficulty to perform this behavior.

Virtual environment became an integral part of the design process by expanding the use of computer-generated models as a design tool to predetermine the appearance and performance of resulting interior architecture under various environmental conditions and how they are expected to affect the human beings and their built environment.

The development of Virtual environment to be based on building information modeling is a development of design method. The nature and power of the design tools available to the designer indicate what he can accomplish. Although BIM is well prepared for a sustainable database, yet it needs to be linked to criteria of available rating systems, so that the outcome of that program will be automatically revised against environmental principles and sustainability guidelines.

\section{References}

Abdel-Hadi, Aleya, \& Aboulgheitb, Iman. (2012). Assessing Housing Interior Sustainability in a New Egyptian City. Procedia - Social and Behavioural Sciences, 565-568

Abdel-Hadi, Aleya. (2012). Culture, Quality of life, Globalization and Beyond Procedia - Social and Behavioural Sciences, 14

Abo Neama, Wael Ahmed Shaaban. (2012). Protect our Environment through Developing Architectural Design towards Sustainability by Applying its Principles into Design Tools. Procedia - Social and Behavioral Sciences, 736

Bako, Zinas Zachariah, \& Jusan, Mahmud Mohd. (2012). Motivational Factors Influencing Housing Interior Finish Choice and Preference. Procedia - Social and Behavioral Sciences, 180

Bertol, Daniela, \& Foell, David. (1997). Designing Digital Space - An Architects Guide to Virtual reality. John Wiley and Sons, Inc., New York, 67, 69, 70, 94, 95, $104,116-118,126,212,221,222,225,310-312$

Coleman, Cindy (2002). Interior Design Handbook of Professional Practice. McGraw-Hill, United States of America, 561, 563, 565, 569, 575, 577

Cottrell, Michelle. (2014). Guide to the LEED ${ }^{\circledR}$ Green Associate V4 Exam. John Wiley \& Sons, Inc., New Jersey, 11, 12

Dong, Wei. (1998). Computer Visualization: An Integrated Approach for Interior Design and Architecture McGraw-Hill, Inc., New York, 4, 6, 10-13, 14, 124, 152, 182, 184

Glanz, Karen, Rimer, Barbara K., \& Viswanath, K. (2008). Health Behaviour and Health Education: Theory, Research, and Practice. (4th ed.). John Wiley \& Sons, Inc., United States of America, 71, 73

Husin, Sharifah Nor Fairuz Syed, \& Harith, Zarina Yasmin Hanur. (2012). The Performance of Daylight through Various Type of Fenestration in Residential Building. Procedia - Social and Behavioral Sciences, 197

Ismail, Faridah, Jabar, Izatul Laili, Janipha, Nurul Afida Isnaini, \& Razali, Rozana. (2015). Measuring the Quality of Life in Low Cost Residential Environment. Procedia - Social and Behavioral Sciences, 272

Isnin Zarina, Ramli, Rohaslinda, Hashim, Ahmad Ezanee, \& Ali, Irwan M. (2012). Sustainable Issues in Low Cost Housing Alteration Projects. Procedia - Social and Behavioral Sciences, 394

Jamaludina, Nazhatulzalkis, Mohammeda, Nurul Izma, Khamidib, Mohd Faris, \& Abdul Wahaba, Suriani Ngah. (2015). Thermal Comfort of Residential Building in Malaysia at Different Micro-Climates. Procedia - Social and Behavioral Sciences, 615

Jones, John Christopher. (1980). Design Methods-seeds of human future; John Wiley \& Sons Ltd., U.K, 3, 4, $10-12$

Ken Sanders, AIA. (1996)._The Digital Architect.John Wiley \& Sons, Inc. New York, 96, 97, 405

Keonil, Nuchnapang, \& Sahachaisaeree, Nopadon. (2012). Architectural Design towards Energy Optimization: A Case of Residential Buildings in Bangkok. Procedia - Social and Behavioral Sciences, 285, 286

Kim, Do-Young, Choe, Yoon, \& Kim, Sung-Ah. (2015). Implementing a Digital Model for Smart Space Design: Practical and Pedagogic Issues. Procedia - Social and Behavioral Sciences, 3306

Lawson, Bryan. (1980). How Designers Think. The Architectural Press Ltd., London, 24-25, 40, 43, 47, 64, 72, 86-99

Mahmud, Shahril Anwar, Ahmad, Abdullah Sani \& Abdullah, Aminatuzuhariah Megat. (2012). Lifestyle Orientation and the Residential Environment: An Exploratory Review. Procedia - Social and Behavioral Sciences, 306 
Memikoğlua, İpek. (2014). Utilization of Second Life as a Tool for Spatial Learning in Interior Architecture. Procedia - Social and Behavioral Sciences, 1289 Musaa, A.R., Abdullaha, N.A.G., Che-Ania, b, A.I., Tawilla, b, N.M., \& Tahira, M.M. (2012). Indoor Environmental Quality for UKM Architecture Studio: An Analysis on Lighting Performance. Procedia - Social and Behavioral Sciences, 318

Nazmy, H.S. (2013). Virtual Environment as a Design Tool for Residential Spaces. (Unpublished master's thesis). Helwan University, Egypt.

Norouzia, Nima, Shabakb, Maryam, Rashid Bin Embic, Mohamed, \& Khand, Tareef Hayat. (2015). The architect, the client and effective communication in architectural design practice. Procedia - Social and Behavioral Sciences, 637

Pieter den Hartog, Johannes. (2004). Designing Indoor Climate: A thesis on the integration of indoor climate analysis in architectural design, $3-5$

Pile, John F. (2007). Interior Design. Pearson Education, Inc., New Jersey, 37, 38, 60-65, 139, 140

Porter, Tom (1979). How Architects Visualize. Cassell Ltd, London, 16, 18, 20, 22, 24, 27, 28, 60-63, 70, 91, 180

91, 180

Haddad, Robert. (2014). Research and Methodology for Interior Designers. Procedia - Social and Behavioral Sciences, 285

Smithies, K. W. (1981). Principles of Design in Architecture. Van Nostrand Reinhold Co. Ltd., New York, 3-5, 34, 35, 39-42, 44-46, 55-57

Suyoto, William, Indraprastha, Aswin, \& Purbo, Heru W. (2015). Parametric Approach as a Tool for Decision-making in Planning and Design Process. Case study: Office Tower in Kebayoran Lama. Procedia - Social and Behavioral Sciences, 328

Unwin, Simon. (1997). Analyzing_Architecture. Routledge, London, 25-27, 29-31, 33, 44, 45, 53, 54, 77, 86-87

Whyte, Jennifer. (2002). Virtual Reality and the Built Environment. Architectural Press, Great Britain, 3, 4, 7. 51, 53, 54-56, 60, 66, 68, 78-80, 92-96 